\title{
ELOGIO DE LA SOMBRA DEL ALMA ${ }^{1}$
}

\author{
Prof. Dr. Mario E. Saiz
}

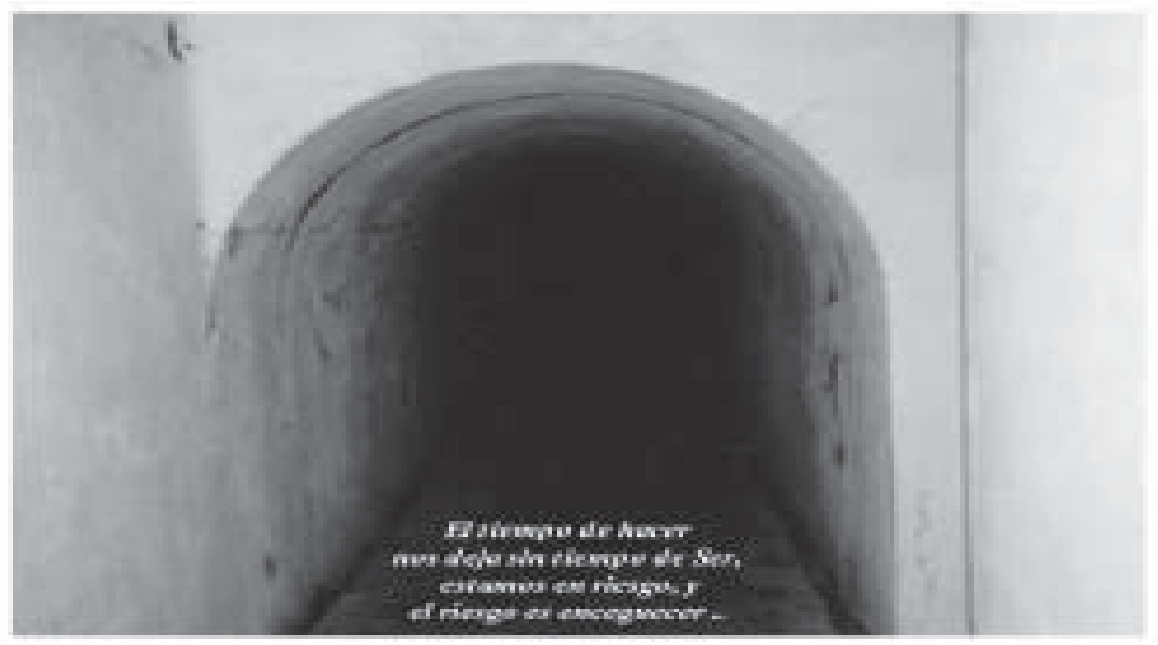

Al detenerme en el tema de este encuentro: Psicología Analítica y Espiritualidad, en conmemoración de los 30 años de la SBPA, mi reflexión me lleva a preguntarme ¿que entendemos por una espiritualidad hecha carne?, es decir, una espiritualidad sentida en las vísceras, en los músculos, en los huesos, en la mente, y por tanto en el alma. En otras palabras, es un preguntarnos por la espiritualidad en nuestra vida cotidiana, en nuestro trabajo, en nuestras relaciones de amor, en nuestros vínculos sociales y profesionales.

La espiritualidad hace referencia a la naturaleza y condición de lo espiritual, entendiendo por Espiritual, todo aquello que trasciende lo físico y que representa lo más esencial de algo. Nuestra circunvalación en torno a la presentación de este tema, lo hemos divido en cuatro episodios, fermentales, inacabados, provocativos y reflexivos, que nacen a partir de la comprensión de dos textos de Jung:

"La sombra, aunque es por definición una figura negativa, muestra sin embargo con bastante frecuencia rasgos o relaciones positivas que remiten a otro trasfondo de índole diferente. Es como si escondiera contenidos significativos bajo una envoltura de poco valor. La experiencia confirma esta suposición, y lo que al parecer estaba encubierto consta por lo general de figuras cada vez más luminosas". C. G. Jung (OC 9/1 \#485).

"Colocar a un hombre ante su sombra significa también mostrar su lado luminoso. Cuando uno se ha visto varias veces juzgando entre opuestos se capta inevitablemente qué quiere decirse con el sí-mismo. Quien percibe al tiempo su sombra y su luz se ve desde muchos lados, y así se coloca en el medio". C. G Jung (OC 10 \# 872)

El Elogio de la sombra del alma, o el alma en la sombra, es la materia que tratan estos apuntes que estamos presentando, donde las reflexiones y las sugerencias son aportes, realizados con cariño y simbólicamente, a los jóvenes terapeutas junguianos, que habitan hoy esta querida casa SBPA, la cual cumple sus primeros 30 años de próspera vida.

PRIMER EPISODIO:

\footnotetext{
${ }^{1}$ Conferencia presentada por el autor en la Pontificia Universidad Católica (PUC-San Pablo), en "Diálogos na contemporaneidade: A Psicología Analítica e a Espiritualidade". En conmemoración de los $30^{\mathrm{a}}$. años de la Sociedade Brasileira de Psicología Analítica (SBPA-Brasil), Septiembre, 2008. (N. E.).
} 


\section{LA SOMBRA DEL ALMA O EL ALMA EN LA SOMBRA?}

Ahora bien, ¿cómo nos aproximamos a una comprensión del Alma? No racionalmente, no mediante definiciones o abstracciones, sino imaginalmente, metafóricamente, simbólicamente. El alma es una metáfora de la psique fecundada por Eros. El alma encarna, corporeiza la emergencia de la psique como humana. Ella emerge en la actividad vinculante que fecunda a Psiqué, que la humaniza en ese trayecto antropológico que transcurre en la circularidad de Eros y de Logos, que crece y se desarrolla a la sombra del Self.

En el proceso de individuación el flujo del Self tiene una primera expresión en el Ego, una segunda en la Sombra, una tercera en el Alma, en tanto, emergencia que surge a la sombra del cuarto, del cual el yo se aleja y el alma se aproxima. ${ }^{2}$

El alma es metafóricamente emergencia de energía vital, de relación primordial, de fuerza vinculante, de tiempo de encuentro. El alma no tiene status de sustancia como el ladrillo en el pilar de una casa, sino como el alma de la casa, que no esta en ningún lugar, sino en todos los lugares de la casa, en tanto, emerge en las relaciones Ego-Self, de las interacciones del ánima-animus con el otro, con el mundo, y con el cosmos. Pero, se trata de una emergencia que no puede ser deducida ni desde el ánima ni desde el animus, es la emergencia de una trascendencia, entre lo conciente e inconsciente, entre lo individual y lo colectivo, es la emergencia de una función trascendente y generatriz de un modo simbólico de ser existencialmente en-el-mundo.

Cuando nos preguntamos por la Sombra del Alma nos acercamos a ese lugar oscuro de su luminosidad, en tanto ella solo emerge como alma a la sombra del cuarto, esto es del Self. La sombra es el hogar donde el Ser se oculta. Un filósofo de Éfeso, Heráclito, llamado el oscuro por Diógenes Laercio ${ }^{3}$, nos dice: "la naturaleza trascendente ama ocultarse" ${ }^{4}$. Por eso, cuando la nada nos conmueve y el vacío nos trae la desesperanza, el alma emerge para transformar el sentido de lo existencial, y posibilitar el reencuentro con el Eros de la vida. De lo contrario, el vacío generado es llenado por el poder, un poder descarnado de Eros, un poder que ennegrece el alma. La negrura de la sombra del alma aliena así la transformación del ser, de la vida, de su cosmovisión, y por tanto, las posibilidades de aproximarse al insondable y misterioso Ser.

El alma emerge, como alma de ser, alma de mundo (ánima-mundis), alma humana (ánimaanimus), donde la coniunctio de de-velar y construir son los dos movimientos recursivos, generatrices de toda la creatividad del encuentro lunar-solar. El alma estremece al yo, es puente emergente entre el polo instintivo y el polo espiritual, es el medium donde despunta el alma que nos anima, que nos animus. Ella es arte, poesía, color, y música, es fuente oscura de sombra, de lo rechazado, reprimido y proyectado, y también, del dolor y el sufrimiento. Fuente a la que volvemos en la noche del alma para alcanzar, en su corporeidad emergente, en su tierra lunar, en su espesura, el sentido perdido, o lo que es lo mismo, la luz oscura del atardecer, que también puede ser, crepuscular.

El alma tardíamente se piensa, solo se siente, solo se intuye, solo es experiencia viva, ya sea como eros o como pathos, como expresión estética, o sentir ético. Expresado en el lenguaje de Heráclito: "Su trama escondida es más fuerte que la manifiesta"

Giorgio Colli, filósofo italiano contemporáneo, escribe: "el mundo tal como se presenta ante nuestros ojos, en general, y en cada configuración particular, es la expresión de algo desconocido, en tanto alusión a algo oculto. Toda representación remite primero a un fondo irrepresentable - la pura inmediatez, por lo cual es más adecuado llamarla expresión, que representación. Pertenece a la naturaleza de la expresión el tener que dejar que se pierda en parte algo, en develar sólo de modo incompleto e imperfecto" (Colli,1996:49-52) . Esta incompletud no impide que el filósofo se exprese diciendo:

"Bello, sin reservas, es el amor a la verdad. Lleva lejos, y es difícil alcanzar el final del camino. Más difícil es, sin embargo, la vía de regreso, cuando se quiere decir la verdad. Querer mostrar la verdad desnuda es menos bello, porque turba como una pasión. Casi todos los buscadores de

2 Ulanov, A. (2007) The third in the shadow of the fourth, Journal of Analytical Psychology, 52:585-605

${ }^{3}$ Diógenes laercio (2007), Vidas y opiniones de los filósofos ilustres, Madrid: Alianza, IX, 5),

${ }^{4}$ Mondolfo, R. (2000) Heráclito. Textos y problemas de su interpretación. Madrid: Siglo Veintiuno,frag.123

${ }^{5}$ Mondolfo, R.(2000) Heráclito. Textos y problemas de su interpretación. Madrid: Siglo Veintiuno, frag. 54

${ }^{6}$ Colli, G. (1996) Filosofía de la expresión, Madrid: Siruela 
la verdad han sufrido esta enfermedad desde tiempos inmemoriales". (Colli, 2008: 21)

En la experiencia común, luz y sombra son correlativos asimétricos: intuitivamente la sombra es inherente a un cuerpo opaco del cual es un natural apéndice, mientras que la luz está fuera de él. Podemos decir, ciertamente que un cuerpo opaco tiene partes "en" luz y partes "en" sombra, más que esta aparente asimetría no anula la asimetría originaria: tenemos una Sombra, el resto "viene" iluminado. ${ }^{8}$ (Trevi,1996)

No tiene importancia que la luz provenga de lo trascendente, de la sociedad, de la cultura o de un conjunto de valor inscriptos en el cuerpo vivo de la humanidad. El individuo tendrá que dar cuentas sólo con la Sombra que deriva de aquella luz que no es suya. Sólo sabemos con certeza que tener experiencia de nosotros es experimentar con una Sombra, que tiende a disimularse o agigantarse para aniquilarnos o escondernos, ya que está en su naturaleza: el amar ocultarse.

Por eso no diremos que la Sombra es meramente lo reprimido, no diremos que es la representante inaceptada de las pulsiones, no diremos que es solo la proyección de la negrura del alma, puesto que siendo esto realidad, la Sombra no se agota en parciales identidades. "La Sombra como metáfora traduce una zona de oscuridad que encierra en si muchas presencias." (Tevi,1996)

Reducir la Sombra al "mal", por ejemplo, es identificarla con uno de sus contenidos, es empobrecerla como experiencia emotiva y simbólica. Es claro que Jung ha diferenciado y desplegado un espectro de la Sombra: persona $l^{9}$, colectiva ${ }^{10}$ y arquetípica ${ }^{11}$, y esta última vinculada al principio del mal (Jung, OC.10 \# 858). Pero en los apuntes de esta presentación, queremos acercarnos a la Sombra del Alma, como metáfora que habla de otra metáfora, como aproximación al insondable Ser. La ocultación del Self, la potencial creatividad del alma, las tendencias y las funciones no desarrolladas de la personalidad, no son por sí mismas el mal, y aún así forman parte de la Sombra.

Para aproximarnos a la Sombra del Alma, exploraremos sus manifestaciones en la expresión literaria, pictórica y poética. Lo haremos en su forma originaria, es decir, presocrática, ya que con Platón se introduce un quiebre, con él la compresión de la sombra se vuelve como el estado más alejado de la verdad. En la alegoría de la caverna la sombra era necesaria como el polo que se opone de manera absoluta a la luz del sol. De allí en adelante, la sombra aparecerá fundamentalmente cargada de negatividad, negatividad que a lo largo de su recorrido por la historia de la representación occidental no llegará a perder jamás, y por eso nos encontramos, transitando, con el alma en la sombra.

\section{SEGUNDO EPISODIO:}

\section{LA TRANSMUTACIÓN DE LA SOMBRA EN LA LITERATURA}

En la sombra de occidente, encontramos como la literatura japonesa nos muestra que la sombra implica una transmutación de lo negativo. Jun'ichirô Tanizaki (1896-1965), uno de los mayores escritores de la narrativa japonesa contemporánea, nos plantea que así como para occidente el más poderoso aliado de la belleza fue siempre la luz; en la estética tradicional japonesa lo esencial está en captar el enigma de la sombra.

Lo bello no es una sustancia en sí sino un juego de claroscuros producido por la yuxtaposición de las diferentes sustancias que van formando el juego sutil de las modulaciones de la sombra. "Así como una piedra fosforescente, colocada en la oscuridad, emite una irradiación, expuesta a la

${ }^{7}$ Colll, G. (2008) La naturaleza ama esconderse, Madrid: Siruela

${ }^{8}$ Trevi, M. (1996) Metáforas del símbolo, Barcelona: Anthropos.

${ }^{9}$ La sombra personal es una diferenciación en la formación del Ego, que se organiza a partir de todos aquellos aspectos de una persona que le resultan inaceptables, rechazados o desagradables de sí misma. En la labor clínica nos encontramos con diversos fenómenos de sombra, entre los cuales están envidia, agresión, avaricia, pereza y celos. Esta no es una lista exhaustiva ni mucho menos, pero puede presentarse proyectada en los otros, hacerse presente en los sueños o en la transferencia analítica.

${ }^{10}$ La Sombra colectiva expresa los contenidos que no pertenecen a la historia personal, sino a todo lo negativo, a todo lo que se opone al espíritu de la época, por ejemplo, hoy día, las cualidades de la sombra colectiva son imputadas al capitalismo o al comunismo, de acuerdo a las convicciones políticas de cada uno.

${ }^{11}$ La Sombra arquetípica emerge de la esfera arquetípica o mitológica del inconsciente colectivo. En el pensamiento de Jung esto equivaldría al mal.

${ }^{12}$ En la cultura japonesa, el toko no ma es una especie de oquedad o "hueco" horadado en una de las paredes 
plena luz, pierde su existencia si se le suprimen los efectos de la sombra" (Tanizaki, 2007:69).

El occidente prefiere lo luminoso, lo pulido, lo resplandeciente y sin manchas, lo rectilíneo y armonioso. El Japón, en cambio, según advierte Tanizaki, opta por el poder sugestivo de la sombra y lo asimétrico. Por ejemplo, cuando nos muestra la oscuridad como la condición indispensable para apreciar la belleza de una laca. (Tanizaki, 2007:35).

Tanizaki describe en páginas tan poéticas como inquietantes, el centro estético y psicológico de la casa tradicional japonesa: el toko no $\mathrm{ma}^{12}$, donde esa oquedad o ese "hueco" en el salón principal, adornado con un cuadro o un ornamento floral, tiene por cometido el de atrapar, profundizar y privilegiar una sombra como punto de arraigo y exploración para la mirada. "Yo mismo cuando era niño- recuerda Tanizaki -, si aventuraba una mirada al fondo del toko no ma de un salón o de una "biblioteca" adonde nunca llegaba la luz del sol, no podía evitar una indefinible aprehensión, un estremecimiento" (Tanizaki, 2007:50)

Donde reside la clave de este misterio? Tanizaki (2007) decide traicionar el secreto: la clave reside en la magia de la sombra; expulsad esa sombra y el toko no ma enseguida recuperara su realidad trivial de espacio vacío y desnudo. Nuestros antepasados han demostrado ser geniales: a ese universo de sombras, que ha sido deliberadamente creado delimitando un nuevo espacio rigurosamente vacío, han sabido conferirles una actualidad estética superior a la de cualquier fresco o decorado.

La belleza de una habitación japonesa, producida únicamente por un juego sobre el grado de opacidad de la sombra, no necesita ningún accesorio. Al occidental que lo ve le sorprende esa desnudez y cree estar tan sólo ante unos muros grises y desprovistos de cualquier ornato, interpretación totalmente legítima desde su punto de vista, pero que demuestra que no ha captado en absoluto el enigma de la sombra. Su elogio nace en que la sombra nos acerca al Ser, nos muestra su enigma en la penumbra, en tanto dejo sentir en mí la profundidad del alma que se revela en su opacidad.

La sombra no es solo una relación, es un vínculo entre la oscuridad y la luz, una no existe sin la otra, algunos pueden definir la luz por la ausencia de oscuridad, o la oscuridad por ausencia de luz, pero ambos se precisan para definirse, ambos forman parte de la totalidad. La sombra es parte de la emergencia del alma. Cuando en la oscuridad algo es iluminado algo nuevo emerge; en la luminosidad, cuando algo es oscurecido, entonces algo nuevo emerge. Por tanto, ¿no sería adecuado decir que la sombra es la metáfora que expresa la opacidad y la luminosidad del alma?

Lo que hace bella al alma es su sombra, es decir, la alteridad de su misterio. No es acaso, la sombra de la propia sombra, el anverso del alma, un camino en nuestra búsqueda de la fuente originaria. No es acaso el Alma como tercero, la que emerge a la sombra del cuarto. Claro que en occidente, también encontramos el encanto y el misterio de la sombra, su valor arquetípico no puede ser suprimido, su encarnación expresiva es propia a cada cultura, y como veremos luego estará presente desde siempre en la pintura, la escultura y la poesía.

Finalmente, Tanizaki escribe: "en lo que a mi respecta, me gustaría resucitar, al menos en el ámbito de la literatura, ese universo de sombras que estamos disipando (...). Me gustaría ampliar el alero de ese edificio llamado "literatura", oscurecer sus paredes, hundir en la sombra lo que resulta demasiado visible y despojar su interior de cualquier adorno superfluo. Y para ver cuál puede ser el resultado, voy a apagar mi lámpara eléctrica" (Tanizaki, 2007:94-5)

Así termina este episodio, así termina el libro de Tanizaki , del cuál he compartido con ustedes estos fragmentos, estos movimientos del alma narrativa, y que él ha llamado "Elogio de la sombra" (Tanizaki, 2007).

\section{TERCER EPISODIO:}

de la estancia principal de la casa.

${ }^{13}$ Plinio, Historia Natural, XXXV,43 , Este pasaje se extrae de la ed. Textos para la historia del Arte, Visor, 


\section{LA “CURA” DE LA SOMBRA EN LOS ORÍGENES DE LA PINTURA}

“..si se sustrae a la personalidad la sombra que le corresponde, se la condena así a ver mutilada su figura. La "figura viva" necesita de profundas sombras para no perder plasticidad. Sin las sombras no es más que una engañosa imagen plana: un niño más o menos bien educado". C.G. Jung, OC 7 \#400

En la pintura, la sombra pierde cualquier connotación negativa. La Sombra es entonces el tono oscuro que subraya y exalta la parte no alcanzada directamente por la luz. Aquí la Sombra no es privación de nada, sino que es la indicación que permite que surjan figuras, que posibilita que el ser se exprese. La corporeidad, el espesor, el relieve y el contraste, se deben a la Sombra. La Sombra adquiere la misma indispensabilidad que el silencio en la música. (Trevi, 1996)

Un escritor latino llamado Plinio, que vivió en Italia (Comum) desde el año 23 al 79 cuando murió, tratando de ayudar a unos amigos en la erupción del Vesubio que sepultó a Pompeya, escribió una Historia Natural de 37 volúmenes, donde nos habla del nacimiento de la pintura en Grecia.

Egipcios y griegos habrían llegado (ille tempore) a la pintura a partir de la sombra, ya que todos reconocen que la pintura consistía en circunscribir con líneas el contorno de la sombra de un hombre. El carácter primitivo de esta primera operación de representación, tal como Plinio lo cuenta, se basa en que el origen de la imagen pictórica no sería el fruto de una observación directa del cuerpo humano y de su representación, sino de fijar la proyección de su sombra. Plinio lo describe de la siguiente manera:

"La primera obra de este tipo la hizo en arcilla el alfarero Butades de Sicción, en Corinto, sobre una idea de su hija, enamorada de un joven que iba a dejar la ciudad: la muchacha fijó con líneas los contornos del perfil de su amante sobre la pared a la luz de una vela. Su padre aplicó después arcilla sobre el dibujo, al que dotó de relieve, e hizo endurecer al fuego esta arcilla con otras piezas de alfarería. Se dice que este primer relieve se conservó en Corinto, en el templo de las Ninfas" 13

Los motivos que llevaron a la joven a calcar la imagen del amante, la razón que impulsó al padre a darle el volumen de que carecía y a colocar finalmente el "simulacro" en el templo se silencian. De acuerdo a los estudios de Victor Stoichita ${ }^{14}$ (2006), catedrático de la Historia del Arte en la Universidad de Friburgo, podemos diferenciar tres momentos constitutivos del relato:

1. La muchacha enamorada tuvo la idea inicial de fijar la imagen mediante el contorno de la sombra. Ella retuvo únicamente la sombra del amante. La ocasión que propicia la creación del primer simulacro imaginal es la partida del amado. El relato no nos dice adónde ni por qué emprende la partida, alude sólo al hecho de que debe irse lejos. La muchacha, al dibujar la sombra, consigue cercar y retener la imagen del amante que se va, creando una figura de sustitución. (Stoichita,2006)

La figura del amante se ha reducido pues a su perfil, a una apariencia sin cuerpo y sin particularidades. La reducción casi total de la luz nos permite apreciar sólo la línea que define y circunda las cosas y las personas. En griego skiá, sombra, conserva esta acepción: perfil, contorno, borde. De ahí el significado de sombra cual contorno. La Sombra que delimitando, permite, capturar, separar, diferenciar. La Sombra es frontería que delimita y abre mundos ${ }^{15}$ (Saiz,,2003).

La significación de este pasaje es importante: se trata, en efecto, de una metafísica de la imagen cuyo origen debe buscarse en la interrupción de la relación erótica, a raíz de la separación, del alejamiento, y en definitiva, de la ausencia del modelo. De ahí, el carácter de "sustituto" que adopta la representación.

Del texto se desprende claramente que la primera función posible de la representación basada en la sombra es la de imagen para el recuerdo, es decir, para hacer presente lo ausente (Stoichita,2006). En este caso, la semejanza (o similitud) de la sombra desempeña un papel esencial. La presencia de lo ausente es lo que la sombra del alma nos posibilita, es la sombra

Madrid, 1987.

${ }^{14}$ Stoichita, V. (2006) Breve historia de la sombra, Madrid: Siruela.

${ }^{15}$ Saiz, M. E. (2003). Latin America: Cartography of Frontiers and Symbolic Interstices. In Proceedings of The Firteenth International Congress for Analytical Psychology, Cambridge, Daimon Verlag. 501-513.

${ }^{16}$ De toda la metafísica primitiva de la sombra, como sombra yacente, en contacto directo con la tierra, y sus relaciones con la muerte, aquí la proyección pone a la sombra de pie, vertical, es esta sombra erecta la que cons- 
de la sombra, como anverso del alma, que desoculta el ser.

Una segunda función posible - nos dice Stoichita - deriva de la imagen/sombra. Se trata de la imagen de la persona con la cual guarda no sólo una relación de semejanza sino también de contacto. La verdadera sombra, siempre cambiante, acompañara al amado en su viaje (la sombra no puede separarse del amado), la imagen de la sombra dibujada en la pared es un reliquia que se opone al movimiento del viaje, adquiriendo así un valor expiatorio y propiciatorio. La sombra se marcha con el viajero, mientras el contorno de esta sombra, fijado en la pared, eterniza una presencia bajo forma de imagen, consolida una instantánea. Conserva una imagen compensatoria del ausente eternamente "vivo", en "pie"16 (Stoichita,2006)..

El contorno nos lleva a la experiencia de la Sombra, a la experiencia del propio límite. La Sombra se escinde en dos aspectos complementarios: por una parte es lo que somos y no queríamos ser, por otra parte, es lo que no somos y queríamos ser. Siguiendo este doble sendero, la Sombra se constituye como un rechazo de lo que somos y sobre el deseo de lo que no somos.

Tener Sombra es soportar este doble camino: rechazo y carencia. Ambos acompañan la percepción de la Sombra para convertirse en sus fundamentales connotaciones emotivas. Ser consciente de si quiere decir vivir en este doble desplazamiento.

En relación con nosotros mismo y en la relación con los demás la Sombra es pues al mismo tiempo peso y carencia. Sufro por los defectos que no me puedo quitar y sufro por las virtudes que no puedo darme. En definitiva, ¿cómo explorar en cada uno de nosotros, esta carencia, y esta ausencia, esta naturaleza que ama ocultarse?

2. Partiendo que el amado muere, la intervención del padre, el alfarero Butades otorga una nueva realidad a esta sombra. El padre da consistencia a la sombra, al espectro como presencia, como recuerdo. Pone arcilla allí donde sólo había contorno de una sombra; da relieve a la forma y luego la endurece con el fuego del horno.

Se logra el primer nivel de realización de la irrealidad: la sombra cobra consistencia. Una lectura del texto nos lleva a la conclusión que Butades realizó una especie de relieve, donde el origen del modelado en arcilla y el de la imagen pintada se confunden, la unidad de ambos se produce en el taller del alfarero. Necesitamos ver el procedimiento simbólico implicado, la imagen de arcilla que fabrica se adapta al célebre topo poético ilustrado por Cicerón ${ }^{17}$ en las Tusculane disputationes: "El cuerpo es como un vaso o como el receptáculo del alma". En este sentido, el cuerpo como receptáculo de la sombra lo podemos reconocer en la obra de Auguste Rodin, en su escultura del cuerpo humano titulada La sombra (1898), creada ocho años después de El pensador (1880-1).

La Sombra ya no es meramente límite, en lugar de ser sólo lo que me falta, la Sombra me define. Allí donde aparentemente viene a faltar la plenitud luminosa que querría tener, allí pues reconozco mi definición. Yo soy propiamente yo mismo allí donde encuentro mi Sombra y la asumo como eso que me diferencia y me define. Hay un movimiento, de oscuridad y carencia, un movimiento que posibilita llevarla de perfil, de línea de contorno, a lo que me define y me diferencia, no solo por lo que rechazo, sino por mi carencia, por lo que se me oculta.

Por tanto, la operación que me permite transformar la Sombra de límite a definición es una típica operación simbólica. Esta "entrelaza", "relaciona", "une", "conecta", la Sombra con el sujeto. La sombra no se limita a estar ahí, sino que me pone en movimiento, me empuja, me estimula. La Sombra revela algo de mí mismo, me conduce donde no quiero andar y donde, por el contrario, adquiero la única posibilidad de reconocerme por lo que soy (Trevi,1996)

Durante la transformación de límite en perfil, de carencia en definición, la Sombra no pierde sus connotaciones. La oscuridad que posee no se resuelve milagrosamente en luz. Su peso permanece tal como era. Pero lo que el hombre quiere no es liberarse del peso, sino encontrarle un sentido. La sombra es un intermedio simbólico, un intersticio entre el Ego y el Self, un espacio térmico de trascendencia, donde ocurre la experiencia del sentido. El destino,

tituye el soporte del simulacro final. (Stoichita,2006)

${ }^{17}$ Cicerón, Tusculane disputationes $(1,52-52)$

${ }^{18}$ Maspéro, G. (1983) Études de Mythologie et d'archéologie égyptiennes. Paris.

19 Trevi, M. (1996) Metáforas del símbolo, Barcelona: Anthropos. 
el azar, el dato originario, y por fin también el cuerpo, son aspectos particulares de la Sombra en los cuales la operación de conversión del límite en definición aparece en modo evidente y masivo (Trevi,1996). Debo asumir el destino no como el límite que quería transgredir sino como el perfil que me define en el cual me reconozco.

3. Finalmente, el transporte del "simulacro" (statua = de pie) de arcilla al templo de Corintio, que nos refiere Plinio, implica que el joven amado muere (que no figura en el relato condensado de Plinio) y que el padre crea un simulacro que tiene la función de doble del desaparecido. Este doble esta provisto de "alma" (bajo la forma de sombra) y de cuerpo (bajo la forma de receptáculo de alma). Este simulacro se convierte en objeto de culto en el templo de Corintio (Stoichita,2006).

Tanto en Egipto como en Grecia la estatua, en tanto sustituto de la persona, se consideraba necesariamente animada. El famoso KA de los egipcios era el alma de las estatuas que representaban el muerto. Como recuerda Máspero ${ }^{18}$ la forma más antigua de que los egipcios visualizaron el alma (Ka) era la sombra. Se trata en este caso de la "sombra clara", de una proyección coloreada pero etérea del individuo, que lo reproduce trazo por trazo. A su vez, la "sombra negra", considerada desde tiempos remotos como el alma misma del hombre, pasó a verse como su doble.

Nos encontramos, en apariencia, frente a dos operaciones opuestas e inconciliables. Una estática y la otra dinámica. En la primera, reconozco la Sombra como constitutiva de mi propia definición y la acepto cual inevitable aspecto de mi forma. En la segunda, reconozco la Sombra como lo que me empuja hacia una meta tan clara como inalcanzable; como aquel si-mismo que no cesa nunca de alejarse a cada esfuerzo que cumplo por alcanzarlo.

La primera desenvuelve la temática del des-ocultarse, la segunda la temática del con-vertirse. Para una no existe otra meta que la de reconocerse, para la otra la meta es lo inaprensible que yo mismo soy y hacia lo cual me muevo aun en el alejamiento sin pausa del horizonte en el que se manifiesta (Trevi,1996).

La imagen que unifica los dos opuestos es la primordial y recurrente experiencia de la Sombra. Es ella que nos hace ser lo que somos y que nos mueve hacia lo que seremos. Hay un doble movimiento de aceptación y de insatisfacción que parece expresarse en la pintura contemporánea.

Vicente Van Gogh, en su pintura El artista en el camino a Tarascon (1888), se representa acompañado de una gran sombra azul oscura que la fuerte luz del mediodía proyecta sobre la tierra arcillosa. Este ir en camino parece mostrarnos un Van Gogh que se funde en su sombra, como una vela ardiente se funde en su propia cera. ¿Se trata de la sombra de una vida llena de tristezas, o de la sombra que nos lleva por enantiodromía, desde la negrura del alma a la luminosidad de la naturaleza del Ser"?

En la obra de Pablo Picasso, especialmente en dos pinturas realizadas en Vallauris, el mismo 29 de diciembre de 1953: La Sombra y la Sombra sobre la mujer nos muestra dos momentos constitutivos de la Sombra. En la pintura La Sombra su corporeización se impone en un primer plano, pero no tiene ningún contacto con el desnudo de mujer. Es un espectro que parece salir del espacio del espectador para entrar en la imagen, como una primera aproximación de algo que se des-oculta, que esta presente pero aún no profundiza su encuentro con la imagen iluminada de la mujer, se diferencia pero no se conecta, no se integra.

En la Sombra sobre la mujer, el espectro parece salir del espacio del espectador como sombra vertical, masculina, que interactúa con el cuerpo horizontal, femenino, donde precisamente, senos, vientre y pubis son como encendidos por la Sombra. Parece que Picasso pone de relieve que el desnudo es el resultado de una proyección, de una actividad de la sombra, ¿acaso la sombra del artista, o se trata de la función arquetípica de la sombra?. La sombra "tiene como efecto la incandescencia del cuerpo femenino, como si, conforme al mito de la sombra, ésta poseyera la virtud mágica de la encarnación, la capacidad de fecundación metafórica" (Stoichita,2006).

Si la pintura La Sombra nos trasmite un cierto "enfriamiento" que nos aleja, expresado en un color dominante de azul, que nos distancia del contacto con el cuerpo femenino; en La sombra sobre la mujer, el rojo marca el "calentamiento" de esta composición, una tonalidad que nos abraza y nos conmueve. Ambas sombras parecen mirar de una manera idéntica, pero ambas

${ }^{20}$ Saramago, J. (2003) Ensayo sobre la ceguera, Suma de letras. Barcelona: Ediciones Santillana. 
escenas tienen características distintas. Es como si la negrura inicial de la sombra, nos conectara en una segunda instancia, con la profundidad del misterioso femenino de la mujer.

El carácter paradójico de la Sombra se hace presente. Por un lado, en La Sombra vemos como ella irrumpe imponiéndose a nuestra mirada, despojando un espacio de luz con su oscura presencia, escapando a cualquier contacto de proximidad, para luego, en La sombra sobre la mujer, transportarnos a una verdad oscurecida que ella ilumina con su presencia corpórea, con el tocar de la Sombra que permite recobrar el Eros de la imagen. ${ }^{19}$ ¿No es acaso que la transmutación de lo negativo de la Sombra nos abre a su función curativa, restauradora del eros femenino, en donde todo se ánima?.

Estas reflexiones me llevan a compartir con ustedes una pintura muy anterior a Picasso, perteneciente a un artista italiano, Masaccio, me refiero al fresco pintado en los años 1427-8, dedicado a San Pedro, y que se inspira en el siguiente texto de los Hechos de los Apóstoles:

"Eran muchos los milagros y prodigios que se realizaban en el pueblo por mano de los apóstoles. Estando todos reunidos en el pórtico de Salomón, nadie de los otros se atrevía a unirse a ellos, pero el pueblo tenía en gran estima. Crecían más y más los creyentes, en gran muchedumbre de hombres y mujeres, hasta tal punto de sacar a las calles los enfermos y ponerlos en los lechos y camillas para que, llegando Pedro, siquiera su sombra los cubriese" Hechos de los Apóstoles: 5:12-15:

En la pintura vemos a Pedro acompañado de Juan y otro adepto difícil de identificar que pasan a lo largo de la calle, a su vez, arrimados a sus muros diversos enfermos esperan la curación. Efectivamente el milagro ocurre ante nuestra mirada. Allí donde el apóstol acaba de pasar dos hombres se levantan: uno de ellos se apoya en un bastón, el otro le da las gracias. Un tercero de rodillas implora la gracia del milagro, y éste puede alcanzarle ya: la Sombra que Pedro proyecta sobre el suelo le ha tocado y el tullido se está levantando. Ahora es un cuarto y último personaje el que parece beneficiarse de los efectos milagrosos de la sombra del apóstol.

¿Cuál es el simbolismo de la sombra en la historia de Pedro?. Los estudios recientes coinciden en que nos hallamos ante una concepción arcaica (arche) originaria, mágica, de la sombra como exteriorización del alma. Relacionemos esto con lo que nos dice Jung en Psicología y Alquimia, a propósito de que el tratamiento psíquico requiere que el "paciente se enfrente con su sombra, esa oscura mitad del alma_.." (OC, 12, \#36)

Nicolás de Lyra (1270-1340), profesor de teología en la Sorbone, en sus comentarios sobre esta obra nos recuerda que los apóstoles tenían el poder de curar a los enfermos tocados con la mano (per tactum manuum), o mediante la palabra (per verbum). Y Pedro era el único que poseía el poder de curar con su sombra (per umbra), lo que era un prodigio mayor.

Curar con la palabra es propio de los hombres que poseen un poder fuera de lo común, en cambio la sombra no es lo mismo. Masaccio insiste en el efecto prodigioso de la sombra en sí misma, su poder milagroso (inexplicable) de curación, y por el otro lado, el poder científico de la sombra a través de la proyección.

La solemnidad de los apóstoles se debe precisamente al hecho de que acaban de salir del espacio sagrado, de ahí deriva su milagroso poder. La sombra de Pedro dotada de poder es la exteriorización de una virtus adquirida en las profundidades misteriosas del templo. Stoichita (2006) comenta que se trata de un precioso trabajo de simbolización mediante el que Masaccio establece una relación simbólica en profundidad entre la sombra que cura (primer plano) y la iglesia (último plano), entre la virtud milagrosa de la sombra y el cielo, considerado simbólicamente, como el verdadero origen de esa virtud.

\section{CUARTO EPISODIO:}

\section{AL ENCUENTRO DE LA SOMBRA EN EL TIEMPO POÉTICO DEL SER}

"Existen muchas cosas que no comprendemos todavía. Se nos presentan in umbra, veladas y envueltas en la oscuridad. Sólo en un momento posterior se hace luz sobre lo que todavía estaba oculto" C.G. Jung (OC.10 \# 866).

El tiempo de hacer no nos deja lugar para el tiempo de Ser. Estamos en riesgo, y el riesgo es enceguecer. Recordemos lo que nos dice Saramago en su "Ensayo sobre la Ceguera", sobre la 
más terrible de las cegueras, la ceguera del alma, que uno de sus personajes expresa diciendo: "...creo que nos hemos quedado ciegos, creo que estamos ciegos. Ciegos que ven, ciegos que viendo no ven"20 (Saramago, 2003).

Jung lo ha escrito a su manera: "todo estaba en la obra, era un símbolo oculto cuya comprensión se nos haría posible mediante la renovación del espíritu de la época: era menester otros nuevos ojos, porque los ciegos no podrían ver más que aquello que tenían la costumbre de ver.." C. G. Jung (OC 14, \# 119).

Pero, ¿dónde encontrar, en nuestra cotidianeidad este tiempo vivido, ese tiempo de individuación que nos sane de la ceguera?

Nos encontramos pues, en la búsqueda de un tiempo perdido, o de lo que podemos llamar un entretiempo, el tiempo que se ubica en el camino del medio, entre las flexiones polares de la ansiedad y la depresión. Este entretiempo es un tiempo del medio, necesario para que la vida se humanice. Es lo que caracterizamos como tiempo de re-flexión, un tiempo necesario para instaurar una nueva temporalidad en nuestra cotidianeidad, un tiempo que posibilite la generación de una conciencia, como transformación y explanación del Ser.

En esta búsqueda, uno de los caminos que nos planteamos es que cada día, cada mañana, generemos un tiempo para experienciar simbólicamente, re-flexionar, pensar, es decir, en otras palabras y en consonancia con su etimología, un tiempo de meditar. Meditar es una palabra que viene del latín "meditari" y significa precisamente: "ejercitarse", "reflexionar". ${ }^{21}$

Retomando nuestra pregunta inicial sobre la espiritualidad en nuestro siglo, un camino de respuesta será encontrar un kairos, un tiempo oportuno para meditar, un kairos para el encuentro vivo con nuestra alma, con el alma de los otros, con el alma del mundo. Si nuestro camino es meditar, y hemos encontrado nuestro estilo personal de hacerlo, la propuesta que sugiero es comenzar este tiempo de meditación, con un meditar en Sombra, como dice Jung, en esa oscura mitad del alma.

Sabemos que todo proceso de individuación implica un trabajo de todos los días y cada día con la Sombra. El primer paso de este trabajo con la sombra comienza con el recoger nuestras proyecciones de la sombra que hemos colocado en el Otro y en el Mundo (no olvidemos que todo lo que admiramos o rechazamos en otros existe en nuestro interior). El segundo paso es reconocer la sombra en nuestros sueños mediante la amplificación y elaboración de los símbolos. El tercer paso es encontrarnos con la sombra en el trabajo de la imaginación activa.

Todas estas modalidades de trabajo y elaboración de la sombra, nos posibilitarán, reconocer la sombra como la riqueza oculta y oscura de nuestra cotidianeidad, desde donde un nuevo sentido existencial emerge a partir de la Sombra, en tanto ella nos inicia en el camino de exploración de nuestro mayor potencial de Ser.

El esbozo de estos apuntes sobre la espiritualidad del siglo XXI es instaurar un nuevo tiempo, un tiempo de elogio, como lo dice Jung: sin la sombra la vida se vuelve vacía y se pierde el sentido. (Jung,O.C.).

El elogio de la sombra del alma tiene el sentido del camino en la revelación del ser y con ello, la posibilidad de construcción de una nueva cotidianeidad. Este elogio de la sombra como fuente de creatividad, y de completud, nos permite comprender la afirmación de Jung, que nace de su experiencia de vida y de su experiencia clínica: "nada puede traer tanta y paz y plenitud como la elaboración de la sombra" (Jung, OC).

Por eso, nuestra propuesta, es comenzar el trabajo de la individuación con una meditación sobre el "Elogio de la sombra del alma" en nuestra propia vida, generando para ello dos tiempos,

\footnotetext{
${ }^{21}$ Así, para este tiempo de reflexión, que modalidad de meditación adoptamos? Necesitamos encontrar o construir nuestro camino de meditación. Tendremos que explorar entre una meditación libre o dirigida, o trascendental, o por el contrario, una meditación con visualización, o una meditación Shamadi (detener la mente en un punto de quietud, ni pensamientos o imágenes, centrada en la respiración o latidos y dejando ir las imágenes y los pensamientos), o una meditación Vipassana (Buda,en que nos concentramos en un solo objeto para analizarlo, dejando fluir la conciencia, tomando temas abstractos, amor, compasión, transitoriedad), o una meditación Zen (Japón , en grupo , con ojos abiertos frente a pared blanca, y concentrada en los ciclos de la respiración).

22 Campbell, J. (1991). El poder del mito. Barcelona: Publicaciones y Ediciones Salamandra

${ }^{23}$ Borges, J. L., (1969). Elogio de la sombra. Buenos Aires: EMECE.
} 
un tiempo de amanecer que transcurre al despertar por la mañana y otro tiempo, al día siguiente, un tiempo de anochecer, que transcurre en vísperas del dormir. Es esta experiencia la que nos permite empatizar con la alternancia de los ritmos diurnos y nocturnos, empatizar con los ritmos circadianos de nuestro psiquismo consciente e inconsciente, para que el día recobre su negrura, y la noche su luz.

En el fondo del abismo surge la voz de la salvación. El momento de mayor negrura es el momento en que está por surgir el verdadero mensaje de transformación. En el momento de mayor oscuridad surge la luz. (Campbell, 1991)22" . En las propias palabras de Jung, "No nos convertimos en seres iluminados visualizando figuras de luz, sino volviéndonos conscientes de nuestra oscuridad" (Jung, OC., 12 ).

La propuesta de un tiempo de meditación, de un tiempo de elogio de la sombra, es un camino o una modalidad para que cada uno se encuentre a sí mismo, reencontrandose con esa naturaleza que ama esconderse. Como dice Goethe: Cuando el hombre no se encuentra a sí mismo, no encuentra nada", o en términos de Jung: "la conciencia humana creó la existencia objetiva y el sentido, y el hombre encuentra su lugar indispensable en el gran proceso del Ser" (Jung, OC ).

Esta es una propuesta de trabajo en el proceso de nuestra individuación, es muy simple y a la vez, muy profunda, es muy fácil de enunciar y es muy difícil de cumplir, requiere de mucha humildad y una alta conciencia ética.

El meditar para integrarse a la cotidianeidad, tiene que consolidarse y para ello recordemos un aporte desde la neurociencia, que nos dice que necesitamos 21 días sostenidos de ensayar una propuesta, para consolidarla en la "circuitería" cerebral, según la plasticidad neuronal. Se trata de alcanzar ese tiempo vivido que se experimenta en el tiempo mítico, en el tiempo sagrado, en el tiempo de amor, en el tiempo de la filosofía, de la música, del arte y de la poesía. A propósito de la poesía, me gustaría compartir con ustedes un poema especial de Jorge Luis Borges ${ }^{23}$ :

La vejez (tal es el nombre que los otros le dan)

puede ser el tiempo de nuestra dicha.

El animal ha muerto o casi ha muerto.

Quedan el hombre y su alma.

Vivo entre formas luminosas y vagas

que no son aún la tiniebla.

Buenos Aires,

que antes se desgarraba en arrabales

hacia la llanura incesante,

ha vuelto a ser la Recoleta, el Retiro,

las borrosas calles del Once

y las precarias casas viejas

que aún llamamos el Sur.

Siempre en mi vida fueron demasiadas las cosas;

Demócrito de Abdera se arrancó los ojos para pensar;

el tiempo ha sido mi Demócrito.

Esta penumbra es lenta y no duele;

fluye por un manso declive

$y$ se parece a la eternidad.

Mis amigos no tienen cara,

las mujeres son lo que fueron hace ya tantos años, las esquinas pueden ser otras,

no hay letras en las páginas de los libros.

Todo esto debería atemorizarme,

pero es una dulzura, un regreso.

De las generaciones de los textos que hay en la tierra 
sólo habré leido unos pocos,

los que sigo leyendo en la memoria,

leyendo y transformando.

Del Sur, del Este, del Oeste, del Norte,

convergen los caminos que me han traído

a mi secreto centro.

Esos caminos fueron ecos y pasos,

mujeres, hombres, agonías, resurrecciones, dias y noches,

entresueños y sueños,

cada infimo instante del ayer

$y$ de los ayeres del mundo,

la firme espada del danés y la luna del persa,

los actos de los muertos,

el compartido amor, las palabras,

Emerson y la nieve y tantas cosas.

Ahora puedo olvidarlas. Llego a mi centro,

a mi álgebra y mi clave,

a mi espejo.

Pronto sabré quién soy.

El poeta inicia este poema diciendo "La vejez (tal es el nombre que otros le dan) / puede ser el tiempo de nuestra dicha. / El animal ha muerto o casi ha muerto./ Quedan el hombre y el alma.» $Y$ al final del mismo nos dice:

\section{"Llego a mi centro, a mi álgebra y mi clave, a mi espejo"}

El encuentro con la Sombra nos define, nos devela caminos hacia el Self, genera la emergencia del alma, disuelve la negación del mal, retira nuestras proyecciones, y en consecuencia, nos aproxima a saber quienes somos, en el insondable y misterioso Ser. En este camino de búsqueda, como nos dice Borges, en el último verso de esta poesía: Pronto sabré quién soy. Con estas palabras el poeta finaliza su poesía, que para vuestro recuerdo, ha llamado "Elogio de la Sombra".

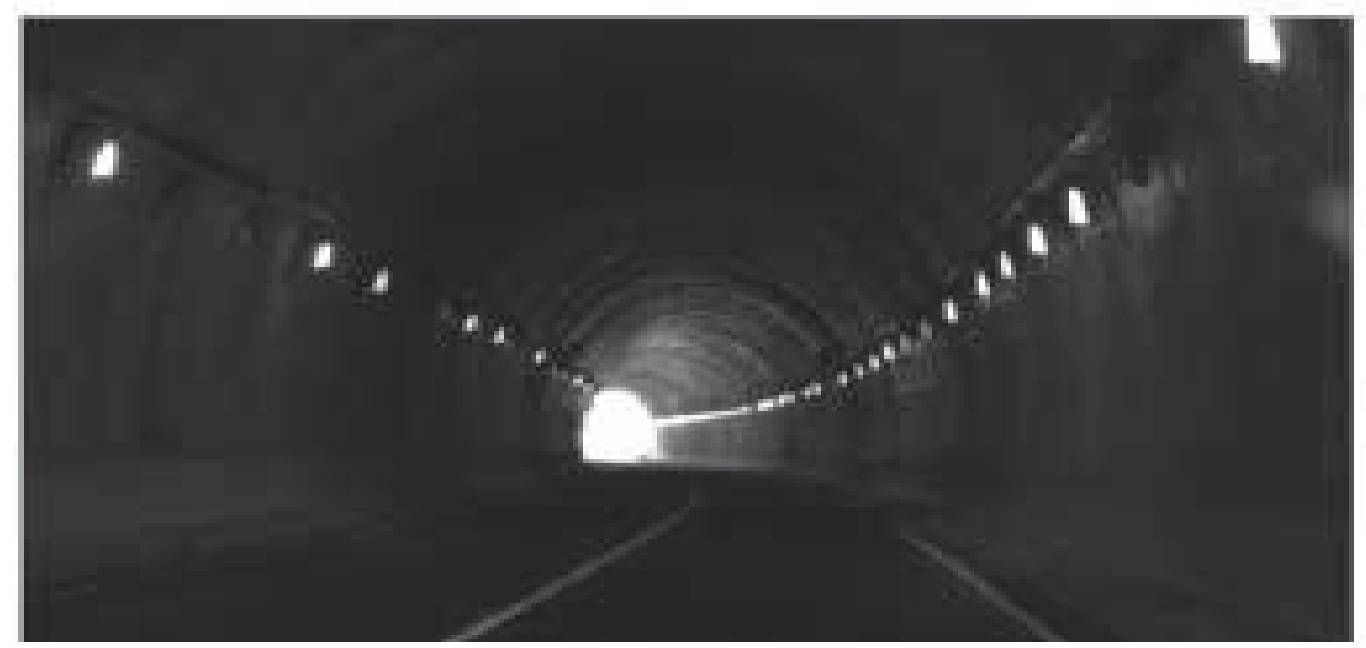

Por ho se we ho sidit. 
El Prof. Mario Eugenio Saiz es un hombre de "dos mundos", que ha sabido mixturarlos. Doctor en Medicina, Psiquiatra y por otro lado Profesor de Filosofia y Analista Jungiano.

Miembro Fundador de la Sociedad Uruguaya de Psicología Analítica y Miembro de la International Association for Analytical Psychology (Zûrich). Postgrado en Psicología Analítica, Profesor Titular en Psicología Clínica Analítica en la Maestría en Psicoterapia Junguiana de la Facultad de Psicología de la Universidad Católica del Uruguay. Profesor Titular en Psicología Analítica en el Magister en Psicología Junguiana , Facultad de Psicología , Universidad Adolfo Ibáñez, Santiago de Chile. Orientador y Responsable de Supervisión Clìnica en varios países de América Latina. (N.E.) 